Вісник Дніпропетровського університету. Серія: геологія, географія. 2016. 24 (1), $27-31$.

Vìsnik Dnìpropetrovs'kogo unìversitetu. Seriâ geologiâ, geographìâ

Dnipropetrovsk University Bulletin. Series geology, geography. 2016, 24 (1), $27-31$.

doi: $10.15421 / 111604$

http://geology-dnu.dp.ua

УДК 556.491:622

\title{
Удосконалення концепції сучасного гідрогеологічного моніторингу локального рівня
}

\author{
Г. П. Євграшкіна, О. Є. Калинкіна, В. В. Проценко
}

Дніпропетровський національний університет імені Олеся Гончара, Дніпропетровськ, Україна, е-таіl: olga_miraclesabadash@mail.ru

Обгрунтовано доповнення до теорії гідрогеологічного моніторингу. Він розглядається як багатоступенева динамічна природно-технічна, просторово-часова система контролю і керування режимом підземних вод зі зворотним зв'язком між контролем і керуванням. Його складові: 1 - режимна спостережна мережа; 2 - епігнозна задача, прогнозна задача; 3 - розроблення комплексу природоохоронних заходів на основі аналізу результатів прогнозу; 4 - втілення розроблених заходів; 5 - режимні спостереження для оцінки ефективності і достатності заходів, їх корегування; 6 прогноз у новій гідрогеологічній ситуації, поліпшеній захисними заходами. Тут має місце зворотний зв'язок: повернення до першого пункту у нових гідрогеологічних умовах.

Ключові слова: гідрогеологічний моніторинг, режимні спостереження, епігноз, прогноз, природоохоронні заходи

\section{Improvement of the concept of modern hydrogeological monitoring local level}

\author{
G. P. Yevgrashkina, O. E. Kalinkina, V. V. Procenko \\ Oles Honchar Dnipropetrovsknational university, Dnipropetrovs'k, Ukraine, e-mail: olga_miraclesabadash@mail.ru
}

Justified additions to the theory of hydrogeological monitoring. It is considered as multistage of dynamic natural-technical, space-time system monitoring and control regime of groundwater feedback between of the control and management. On the based analysis, generalization and improvement of previous studies the author's offer version of the hydrogeological monitoring, which consists of such parts. 1. Study of changes in the groundwater regime in space and time on the technologically impaired territory where created monitoring observation. She is the first mandatory and the most important part, initial source of information for the organizations of a permanent monitoring each of the three levels - global, regional and local. For the scientific basis her structure used hydrodynamic methods. 2. Complex calculations, which consists with inverse and direct, epignozn and prognosis, inductive, inverse and generalized hydrogeological tasks. 3. Development of environmental protection measures on basis of the hydrogeological areas of multivariate prognosis studies. 4. The embodiment of developed actions. 5. The regime observations for assess the effectiveness and adequacy measures. 6. Adjustment measures prognosis in new hydrogeological situation improved protective measures. Again, monitoring observations and their analysis. Here have the feedback and return to the first item in new hydrogeological conditions. The focus is on solving the inverse task numerical method using the equations filtration and mass transfer in finite difference form of explicit and implicit schemes. The made conclusions that numerical methods make it possible to determine the design parameters of generalizing. In the inverse task explicit and implicit schemes are characterized by the same accuracy, but the results are different, because the explicit scheme characterizes the dispersion of the beginning in the billing period, and implicit in his end.

Keywords: hydrogeological monitoring, monitoring observations, epignoz, prognosis, environmental protection measures

Вступ. Концепція моніторингу на початку 1970 років розвивалась у його дослівному розумінні як спостереження за станом навколишнього середовища (Tjutjunova, 1987). Але вже в 1979 році Ю. А. Ізраель (Izrajel', 1979) трактує це поняття як цілеспрямовану програму спостережень, оцінки і прогнозу антропогенних змін природного середовища. Подальшого розвитку теорія моніторингу набула у працях (Gamburtsev, 1994; Kajakin, 1999; Mironenko 1998) та інших.
На основі аналізу, узагальнення і удосконалення попередніх досліджень пропонуємо авторський варіант (Yevgrashkina, 2003) гідрогеологгічного моніторингу, який складається 3 таких частин:

1. Вивчення зміни режиму підземних вод у просторі i часі на техногенно порушеній території, де створюється спостережна мережа свердловин. 
2. Комплекс розрахунків, який складається 3 інверсних, прямих - епігнозних і прогнозних та інших гідрогеологічних задач.

3. Розроблення природоохоронних заходів гідрогеологічного спрямування на основі багатоваріантних прогнозних досліджень.

4. Втілення розроблених заходів.

5. Режимні спостереження для оцінювання ефективності і достатності заходів.

6. Корегування заходів, прогноз у новій гідрогеологічній ситуації, поліпшеній захисними заходами. Знову режимні спостереження і їх аналіз. Тут має місце зворотний зв'язок:

повернення до першого пункту у нових гідрогеологічних умовах.

Матеріали і методи досліджень. Джерелом початкової інформації для організації постійно діючого моніторингу кожного 3 трьох рівнів глобального, регіонального і локального - $\epsilon$ режимна спостережна мережа - перша, обов'язкова і найважливіша його складова. Вона дає можливість розв'язати інверсні фільтраційні і міграційні задачі з визначення гідрогеологічних параметрів у другій частині моніторингу. Для визначення швидкості фільтрації $V$ застосовуємо закон Дарсі:

$$
V=-K \frac{\partial H}{\partial x}
$$

Коефіцієнт гідродисперсії $D$ доцільно розрахувати з рівняння руху і збереження маси речовини виду:

$$
D \frac{\partial^{2} C}{\partial x^{2}}-V \frac{\partial C}{\partial x}=m \frac{\partial C}{\partial t}
$$

У рівняннях (1) - (2) використано такі позначення:

$V$ - швидкість фільтрації, м/добу;

$K$ - коефіцієнт фільтрації, м/добу;

$H$ - гідродинамічний напір, м;

$D$ - коефіцієнт гідродисперсії, м²/добу;

$C$ - мінералізація підземних вод, г/дм ${ }^{3}$;

$x$ - просторова координата, м;

$t$ - часова координата, доба;

$m$ - активна пористість, частки одиниці.
Результати i їx аналіз. Розв'язання інверсної задачі розглянуте на прикладі території, прилеглої до ставка-накопичувача «Балка Таранова». Ствір спостережних свердловин (рис. 1) розташований за токовою лінією. Результати режимних спостережень наведено у таблиці 1. Визначення параметрів виконуємо чисельним методом. Рівняння (1) і (2) записуємо у кінцеворізницевій формі для усіх семи свердловин створу.

$$
V=-K \frac{H_{i-1}-H_{i}}{x_{i-1}-x_{i}}, V_{1-2}=-K \frac{H_{1}-H_{2}}{-x_{1,2}}, V_{6-7}=-K \frac{H_{6}-H_{7}}{-x_{6,7}},
$$

де $H_{i-1}, H_{i}, H_{1}, H_{2}, H_{3}, H_{4}$ - абсолютні відмітки рівня підземних вод у загальному вигляді 3 індексами $i-1, i$, та у конкретних свердловинах 1 ,
$2,6,7, \mathrm{~m} ; x_{i}, x_{i-1}-$ координати розрахункових точок у загальному вигляді, м; $\Delta x_{1,2}, \Delta x_{6,7}-$ відстані між відповідними свердловинами, м.

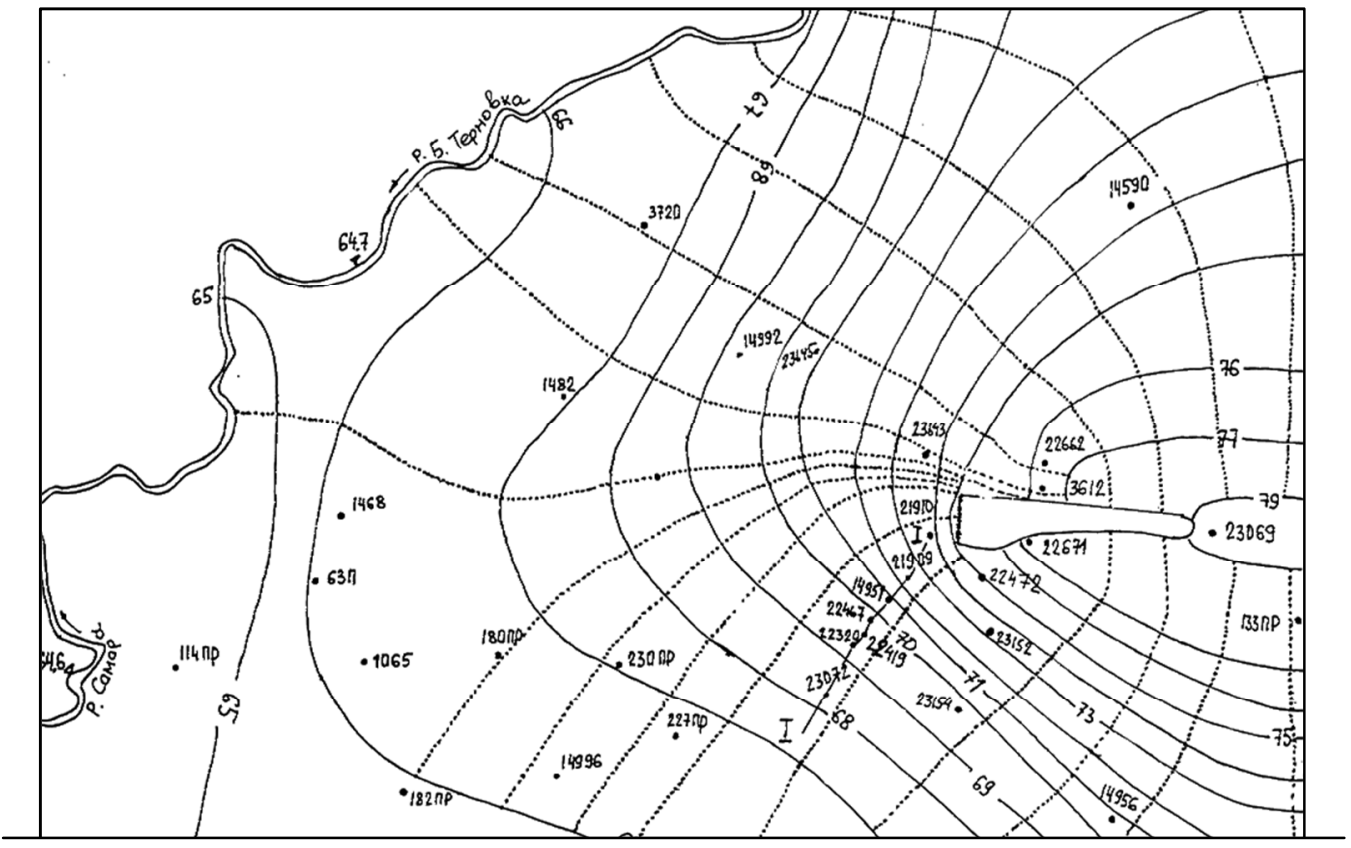

Рис. 1. Схема режимної спостережної мережі на ділянці «Балка Таранова» 
Для розрахунків коефіцієнта гідродисперсії $D$ складаємо систему кінцево-різницевих рівнянь (4) - (8) і розв'язуємо ії відносно параметра $D$.

Результати розрахунків наведено в таблиці 2 і на рисунку 2.

$$
\begin{aligned}
& D_{1,2}\left(\frac{C_{1}^{\tau+1}-C_{2}^{\tau+1}}{\Delta x_{1,2}}-\frac{C_{2}^{\tau+1}-C_{3}^{\tau+1}}{\Delta x_{2,3}}\right) \div \frac{\Delta x_{1,2}+\Delta x_{2,3}}{2}-V_{1,3} \frac{C_{1}^{\tau+1}-C_{3}^{\tau+1}}{\Delta x_{1,2}+\Delta x_{2,3}}=m \frac{C_{2}^{\tau+1}-C_{2}^{\tau}}{\Delta t}, \\
& D_{2,3}\left(\frac{C_{2}^{\tau+1}-C_{3}^{\tau+1}}{\Delta x_{2,3}}-\frac{C_{3}^{\tau+1}-C_{4}^{\tau+1}}{\Delta x_{3,4}}\right) \div \frac{\Delta x_{2,3}+\Delta x_{3,4}}{2}-V_{2,4} \frac{C_{2}^{\tau+1}-C_{4}^{\tau+1}}{\Delta x_{2,3}+\Delta x_{3,4}}=m \frac{C_{3}^{\tau+1}-C_{3}^{\tau}}{\Delta t}, \\
& D_{3,4}\left(\frac{C_{3}^{\tau+1}-C_{4}^{\tau+1}}{\Delta x_{3,4}^{\tau}}-\frac{C_{4}^{\tau+1}-C_{5}^{\tau+1}}{\Delta x_{4,5}}\right) \div \frac{\Delta x_{3,4}+\Delta x_{4,5}}{2}-V_{3,5} \frac{C_{3}^{\tau+1}-C_{5}^{\tau+1}}{\Delta x_{3,4}+\Delta x_{4,5}}=m \frac{C_{4}^{\tau+1}-C_{4}^{\tau}}{\Delta t}, \\
& D_{4,5}\left(\frac{C_{4}^{\tau+1}-C_{5}^{\tau+1}}{\Delta x_{4,5}}-\frac{C_{5}^{\tau+1}-C_{6}^{\tau+1}}{\Delta x_{5,6}}\right) \div \frac{\Delta x_{4,5}+\Delta x_{5,6}}{2}-V_{4,6} \frac{C_{4}^{\tau+1}-C_{6}^{\tau+1}}{\Delta x_{4,5}+\Delta x_{5,6}}=m \frac{C_{5}^{\tau+1}-C_{5}^{\tau}}{\Delta t}, \\
& D_{5,6}\left(\frac{C_{5}^{\tau+1}-C_{6}^{\tau+1}}{\Delta x_{5,6}}-\frac{C_{6}^{\tau+1}-C_{7}^{\tau+1}}{\Delta x_{6,7}}\right) \div \frac{\Delta x_{5,6}+\Delta x_{6,7}}{2}-V_{5,7} \frac{C_{5}^{\tau+1}-C_{7}^{\tau+1}}{\Delta x_{5,6}+\Delta x_{6,7}}=m \frac{C_{6}^{\tau+1}-C_{6}^{\tau}}{\Delta t},
\end{aligned}
$$

де $\Delta x$ - відстань між свердловинами, м;

$\Delta t$ - інтервал спостережень у часі, доб.;

$\tau, \tau+1$ - часові індекси;

$C_{1}, C_{2}, C_{3}, C_{4}, C_{5}, C_{6}, C_{7}-$ мінералізація води у відповідних свердловинах, г/дм ${ }^{3}$.
Вони свідчать, що для досліджуваної території характерна розрахункова схема «макродисперсія». Коефіцієнт макродисперсії

\begin{tabular}{|c|c|c|c|c|c|c|c|}
\hline \multirow{5}{*}{$\begin{array}{c}\text { Дата } \\
\text { спостережень }\end{array}$} & \multicolumn{7}{|c|}{ Значення мінералізації $C, \Gamma /$ дм $^{3}$} \\
\hline & \multicolumn{7}{|c|}{ Свердловини } \\
\hline & 21910 & 14950 & 14951 & 22467 & 22319 & 22320 & 23072 \\
\hline & \multicolumn{7}{|c|}{ Умовний номер свердловин } \\
\hline & 1 & 2 & 3 & 4 & 5 & 6 & 7 \\
\hline 10.IV.81 & 10,6 & 4,3 & 2,7 & 2,2 & 2,0 & 1,9 & 1,85 \\
\hline 11.XI.81 & 11,1 & 4,7 & 2,9 & 2,3 & 2,0 & 1,9 & 1,85 \\
\hline 25.X.82 & 16,6 & 8,4 & 5,9 & 2,8 & 2,6 & 2,5 & 2,4 \\
\hline 24.IV.83 & 11,4 & 8,8 & 6,2 & 3,0 & 2,7 & 2,6 & 2,4 \\
\hline $28 . X I I .84$ & 11,3 & 7,85 & 6,16 & 4,2 & 3,3 & 2,0 & 1,05 \\
\hline 06.IV.90 & 11,4 & 9,5 & 8,9 & 7,4 & 6,2 & 5,0 & 2,9 \\
\hline 21.XII.90 & 11,5 & 9,9 & 9,1 & 7,5 & 6,3 & 5,0 & 2,9 \\
\hline 14.XI.91 & 11,03 & 6,20 & 7,52 & 8,93 & 11,49 & 3,22 & - \\
\hline 09.IV.92 & 10,24 & 6,06 & 7,20 & 8,14 & 13,35 & - & - \\
\hline 22.X.93 & 11,10 & 5,39 & 5,74 & 7,07 & 12,10 & 2,16 & - \\
\hline 30.XI.94 & 9,54 & 5,10 & 6,14 & 6,55 & 10,57 & 11,09 & - \\
\hline 10.X.95 & 9,73 & 4,72 & 4,90 & 5,67 & 7,01 & 2,27 & - \\
\hline 12.VIII.97 & 9,11 & 4,66 & 4,52 & 5,34 & 7,5 & - & - \\
\hline $\begin{array}{l}\text { Відстань між } \\
\text { свердловинами }\end{array}$ & 150 & & & & & & 250 \\
\hline
\end{tabular}
максимальний біля ставка і зменшується в бік річки. У часі він збільшується.

Режимні спостереження по створу ставок «Б. Таранова» - свердл. 23072 
Результати визначень коефіціснта гідродисперсії

\begin{tabular}{|c|c|c|c|c|c|c|c|c|}
\hline \multicolumn{2}{|c|}{ Дата спостережень } & \multirow{2}{*}{$\begin{array}{c}\text { Умовний } \\
\text { номер } \\
\text { свердло- } \\
\text { вини }\end{array}$} & \multicolumn{2}{|c|}{$\begin{array}{l}\text { Мінералізація } \\
\text { води } C, \text { г/дм }{ }^{3}\end{array}$} & \multirow{2}{*}{$\begin{array}{c}\text { Відстань між } \\
\text { свердло- } \\
\text { винами } \Delta x, \text { м }\end{array}$} & \multirow{2}{*}{$\begin{array}{c}\text { Швидкість } \\
\text { фільтрації } V \text {, } \\
\text { м/добу }\end{array}$} & \multirow{2}{*}{$\begin{array}{c}\text { Інтервал } \\
\text { спостережень у } \\
\text { часі } \Delta t, \text { доба }\end{array}$} & \multirow{2}{*}{$\begin{array}{c}\text { Коефіцієнт } \\
\text { гідродисперсії } D \text {, } \\
\text { м²/добу }^{2}\end{array}$} \\
\hline$\tau$ & $\tau+1$ & & $\tau$ & $\tau+1$ & & & & \\
\hline 1 & 2 & 3 & 4 & 5 & 6 & 7 & 8 & 9 \\
\hline \multirow[t]{7}{*}{$10 . I V .81$} & 11.XI.81 & 1 & 10,6 & 11,1 & \multirow{3}{*}{$\begin{array}{l}150 \\
330\end{array}$} & 0,0297 & 215 & \multirow{2}{*}{9,95} \\
\hline & & 2 & 4,3 & 4,7 & & 0,0297 & 215 & \\
\hline & & 3 & 2,7 & 2,9 & & 0,0221 & 215 & \multirow{2}{*}{$\begin{array}{l}4,94 \\
3,71\end{array}$} \\
\hline & & 4 & 2,2 & 2,3 & 140 & 0,008 & 215 & \\
\hline & & 5 & 2,0 & 2,0 & \multirow{3}{*}{$\begin{array}{l}200 \\
170 \\
250\end{array}$} & 0,008 & 215 & \multirow{3}{*}{$\begin{array}{r}2,57 \\
1,6 \\
1,09\end{array}$} \\
\hline & & 6 & 1,9 & 1,9 & & 0,008 & 215 & \\
\hline & & 7 & 1,85 & 1,85 & & & 215 & \\
\hline \multirow[t]{7}{*}{$25 . X .82$} & 24.IV.83 & 1 & 16,6 & 11,4 & \multirow{3}{*}{$\begin{array}{l}150 \\
330\end{array}$} & 0,0297 & 183 & \multirow{2}{*}{15,7} \\
\hline & & 2 & 8,4 & 8,8 & & 0,0221 & 183 & \\
\hline & & 3 & 5,9 & 6,2 & & 0,008 & 183 & \multirow{2}{*}{6,97} \\
\hline & & 4 & 2,8 & 3,0 & 140 & 0,008 & 183 & \\
\hline & & 5 & 2,6 & 2,7 & \multirow{2}{*}{170} & 0,008 & 183 & \multirow{3}{*}{$\begin{array}{l}2,92 \\
1,80\end{array}$} \\
\hline & & 6 & 2,5 & 2,6 & & 0,008 & 183 & \\
\hline & & 7 & 2,4 & 2,4 & 250 & & 183 & \\
\hline
\end{tabular}

$D, \mathrm{~m}^{2} /$ доб

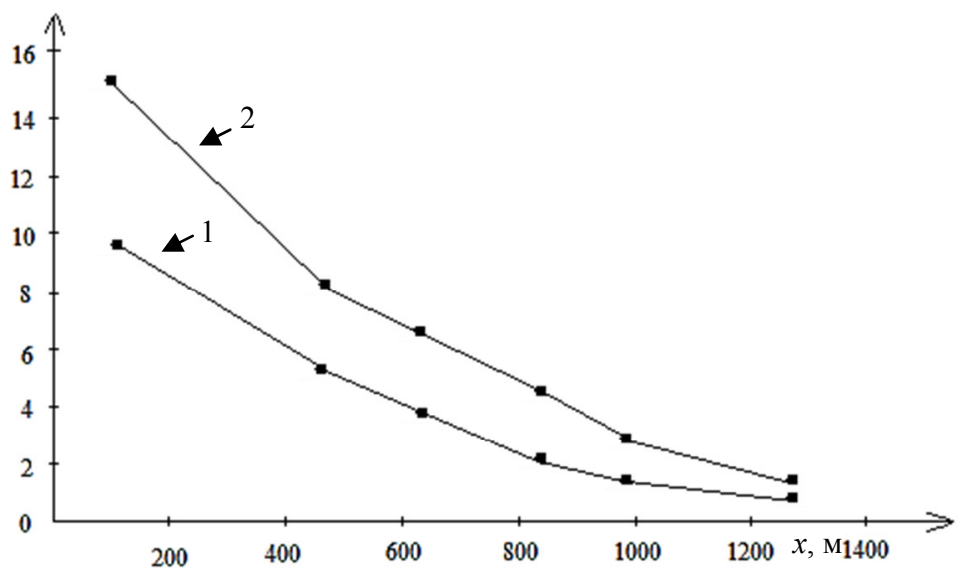

Рис. 2. Зміна параметра $D$ у просторі та часі:

1, 2 - відповідно попередній і наступний моменти часу

\section{Висновки}

1. Числові методи дають можливість визначити узагальнені розрахункові параметри.

2. В інверсній задачі явні та неявні схеми характеризуються однаковою точністю, але результати відрізняються, тому що явна схема характеризує розсіювання на початок розрахункового періоду, а неявна - на його кінець.
3. Числові методи визначення міграційних параметрів мають переваги перед аналітичними в тому, що для прямої задачі застосовується таке саме рівняння, як і для інверсної.

4. Величина параметра $D$ прямо пропорційно залежить від мінералізації підземних вод. 


\section{Бібліографічні посилання}

Tjutjunova, F. M., 1987. Gidrogeohimija tehnogeneza [Hydrogeochemistry technogenesis]. M.: Nauka, 375, (in Russian).

Izrajel', Ju. A., 1979. Global'naja sistema nabljudenij: prognoz i ocenka izmenenij sostojanija okruzhajushhej sredy. Osnovy monitoringa. [Global Observing System: forecast and assessment of environmental changes. Based monitoring]. Meteorology and hydrology. Moscow, 7, 54-67, (in Russian).

Gamburtsev, A. G., 1994. Koncepcija monitoringa prirodno-tehnicheskih. [The concept of monitoring of natural-technological systems]. Geoecology. M.: Nauka, 12-19, (in Russian).
Kajakin, A. O., 1999. Prognoz chrezvychajnyh situacij, svjazannyh s tehnogenno-prirodnymi processami i obespecheniem bezopasnosti objektov. [Prognosis of emergencies related to technogenic-natural processes and security provision of objects]. Geoecology. - M.: Nauka, 101-110, (in Russian).

Mironenko, V. A., 1998. Problemy gidrojekologii [Problems of Hydrogeology]. M.: MSU, (3), (in Russian).

Yevgrashkina, G. P., 2003. Vlijanie gornodobyvajushhej promyshlennosti na gidrogeologicheskie $i$ pochvenno-meliorativnye uslovija territorij [The impact of mining on the hydrogeological and soilreclamation conditions of the territory]. Dnipropetrovsk, Monolit, 200, (in Russian).

Надійшла до редколегії 23.12.2015 